\title{
Correction to: Consequences of the physical nature of the parent material for pedogenesis, nutrient availability, and succession in temperate rainforests
}

\author{
Benjamin L. Turner • Andrew Wells • \\ Kelly M. Andersen • Leo M. Condron
}

Published online: 27 April 2018

(C) Springer International Publishing AG, part of Springer Nature 2018

Correction to: Plant Soil (2018) 423, 533-548.

https://doi.org/10.1007/s11104-017-3514-4

In the original article, Fig. 3 was mistakenly replaced by a copy of Fig. 2. The correct version of Fig. 3 is published here.

The online version of the original article can be found at https://doi.org/10.1007/s11104-017-3514-4

B. L. Turner $(\bowtie)$

Smithsonian Tropical Research Institute, Apartado 0843-03092,

Balboa, Ancon, Republic of Panama

e-mail: TurnerBL@si.edu

A. Wells · L. M. Condron

Agriculture and Life Sciences, Lincoln University, PO Box 85084, Lincoln, 7647 Christchurch, New Zealand

K. M. Andersen

College of Life and Environmental Sciences, University of Exeter,

Exeter EX4 4RJ, UK 
Fig. 3 Concentrations of (a) total carbon, (b) total nitrogen, (c) total phosphorus, and the ratios of (d) carbon to nitrogen, (e) carbon to phosphorus, and (f) nitrogen to phosphorus, in organic and surface mineral soils along the Arawhata chronosequence, Westland, New Zealand
- Organic horizon

- - - Mineral soil (fine earth)


Dune age (years B.P.) 